\title{
HACIA UNA NUEVA EDUCACIÓN
}

\author{
Ronald Casas Ulate ${ }^{1}$ \\ Docente en la Escuela de Filosofía de la Universidad Nacional \\ Heredia, Costa Rica \\ Felipe Ovares Barquero ${ }^{2}$ \\ Docente en la Escuela de Informática de la Universidad Nacional \\ Heredia, Costa Rica \\ José Alberto Rubí Barquero 3 \\ Docente en la Escuela de Filosofía de la Universidad Nacional \\ Heredia, Costa Rica
}

Recibido: 19 de julio, 2007 - Aprobado: 23 de octubre, 2007

Resumen: En este ensayo, centrado en el tema de la Educación, señalamos los principios básicos que configuran el modelo educativo de la era industrial. Para este fin utilizamos los resultados que Alvin Toffler da a conocer en su libro La tercera ola. Estos principios son: uniformización, especialización, sincronización, concentración, maximización y centralización. Tras destacarlos y mostrar cómo cada uno de estos principios deja su impronta en la educación formal del período industrial, defendemos la tesis de que la Nueva educación nace y se configura en un proceso de desmontaje y sustitución por principios del industrialismo por los nuevos principios de la naciente sociedad post-industrial, también llamada Sociedad del conocimiento.

Palabras clave: Uniformización, especialización, sincronización, concentración, maximización, centralización.

Abstract: We point out in this article centered on Education the main principles that shape the educational model of the industrial age. Those principles were explained by Alvin Toffler in his book The Third Wave. They are: standardization, specialization, synchronization, concentration, maximization and centralization. After emphasizing them and showing how each one of them leaves its mark in the formal education in the industrial age, we defend the thesis that the new education is originated and configures itself in a process of dismantling and replacement of the principles of the industrialism by the new principles of the raising post-industrial society, also called Society of the Knowledge.

Key words: Uniformation, specialization, synchronization, concentration, maximization, centralization.

Licenciado en Filosofía de la Universidad de Costa Rica y profesor en la Escuela de Filosofía de la Universidad Nacional. rcasas@una.ac.cr 


\section{Introducción}

Nuestra educación formal está inspirada en el modelo fabril propio de la era industrial. Basta, en efecto, con ingresar en una escuela primaria o en un colegio y darle una mirada a la forma en cómo, ahí, están organizadas las cosas y las personas, para advertir, de inmediato, la similitud que guarda con el modelo que le sirve de inspiración.

Esto se explica porque, según Toffler (1980), al "extenderse el industrialismo por el Planeta, se hizo visible su diseño oculto. Se componía de seis principios interrelacionados que programaban el comportamiento de millones de personas" (p. 59). Esos principios aludidos son los siguientes: uniformización, especialización, sincronización, concentración, maximización y centralización

Estos seis principios conforman el código oculto que explica el funcionamiento de la civilización industrial, en general, y de su modelo educativo en particular; son como las creencias básicas, comunes a todas las sociedades que pasaron a formar parte del industrialismo y, como tales, más implícitas que explícitas. Su activa presencia sólo se torna evidente a la luz de la crisis del modelo civilizatorio, basado en el industrialismo.

\section{Principios del Código oculto}

Por lo anterior, el camino por seguir en este trabajo consiste en mostrar cómo cada uno de estos principios ayudó a configurar el peculiar modelo educativo de la era industrial, y cómo su desmontaje y sustitución por principios de signo contrario contribuye a la visualización de una nueva educación que sirva de partera a una nueva civilización. 


\section{Uniformización}

Este principio, animador de la producción industrial, mucho más débil en la anterior forma de producción artesanal, también se puede apreciar formando parte de la educación de la era industrial. En efecto, de la misma forma que en las fábricas se producen cientos y miles de artículos iguales, en las escuelas el proceso educativo busca producir personas iguales mediante procedimientos organizativos calcados de los usados en las fábricas. Pero, como las personas, ni cuando niños, ni cuando jóvenes, ni cuando adultos, ni nunca, son iguales, esta estrategia educativa de echarlas a todas en el mismo saco, de querer lograr con todas el mismo resultado, en muchos aspectos, ha sido un fracaso.

Si tal cometido no funcionó de la mejor manera en la época industrial, menos ahora que se está dando un cambio hacia nuevas formas de producción y, en general, hacia una nueva civilización. Dada esta transición, de las sociedades industriales a las postindustriales, el hecho de que el sistema educativo insista en ignorar el cambio y que siga comportándose como lo hacía en el siglo XIX, resulta cada vez más patético. No sin razón, este sistema uniformizador obliga a tantos estudiantes a salir sin terminar el proceso, con las graves consecuencias que ese abandono temprano tiene para muchos; abandono que el sistema disfraza llamándolo deserción, un término que, astutamente, culpa al estudiante de su ineptitud para adaptarse a un esquema rígido, rutinario y aburrido.

En estas circunstancias, lo extraordinario es que algunos sobrevivan sin dejar en el camino el tesoro de potencialidades con el que todos nacemos.

\section{Especialización}

Adam Smith se convirtió, entre otros, en un conocido divulgador de las ventajas de la división del trabajo, es decir, de la especialización. Y este principio de dividir el todo en sus partes, ganó tanto terreno que pasó a caracterizar, como uno de sus pilares, la visión moderna del mundo, la que proponen Descartes y Bacon, la que encuentra su fundamentación científica 
en la físico-matemática de Newton. De aquí que la educación moderna le rinda culto a la especialización, que se estructure, curricularmente, a partir de una teoría del conocimiento fragmentaria, en la que la realidad está lejos de ser vista como una unidad que interconecta todos sus elementos.

Los resultados de esta fragmentación del conocimiento en compartimentos estancos, Ilevaron al filósofo español Ortega y Gasset (2006) a hablar del bárbaro especializado, del que por saber mucho de poco cree que puede hablar con propiedad de todo. También Marcuse (1969), con una visión crítica más sistémica, habló del hombre unidimensional. Se trata, ciertamente, de un principio que aplicado a la educación contribuye a crear esa sensación, para nada conveniente, de estar separados del todo, de ser como las mónadas de Leibnitz: unidades incomunicadas por carecer de puertas y ventanas.

\section{Sincronización}

La importancia de este principio queda confirmada con el hecho de que la proliferación de relojes, de pared y de bolsillo, se da "en el momento exacto en que la revolución industrial exigió una mayor sincronización del trabajo" (Toffler, 1980, 64).

Igual que con los principios de uniformización y de especialización, la sincronización también pasa a formar parte del currículo oculto de la educación de toda la era industrial.

Al respecto, Toffler (1980) señala:

No fue una coincidencia el que en las culturas industriales se les enseñara a los niños, ya desde temprana edad, a tener conciencia del tiempo. Se condicionaba a los alumnos a llegar temprano a la escuela cuando sonaba la campana, a fin de que, más tarde, pudiera confiarse en que llegaran a la fábrica o a la oficina cuando sonaba la sirena. Los trabajos fueron cronometrados y divididos en secuencias medidas en fracciones de segundo. De nueve a cinco formaba el marco temporal para millones de trabajadores (p. 64).

La aplicación irrestricta de la sincronización, con las características anotadas, al campo de la educación, nos lleva a preguntarnos si procesos como el aprendizaje, la creatividad, el desarrollo físico y emocional, entre otros, rinden sus mejores frutos en un ambiente tan 
imbuido del espíritu fabril. De hecho, para muchos el paso de la vida campesina a la vida urbana, del trabajo artesanal al industrial, fue un paso traumatizante.

\section{Concentración}

Con el advenimiento de la civilización industrial, se pasa de la dispersión de las fuentes de energía a la dependencia, casi exclusiva, de depósitos altamente concentrados de combustible fósil.

Esta concentración en una principal fuente de energía, se acompaña con otras concentraciones complementarias. "De hecho, se ha denominado a los comienzos del siglo XIX la época de los grandes encarcelamientos, los delincuentes eran concentrados en cárceles, los enfermos mentales eran concentrados en manicomios y los niños lo eran en escuelas, del mismo modo que los obreros eran concentrados en fábricas" (Toffler, 1980, 66).

Hacer de la escuela el topos oficial de la educación tiene múltiples consecuencias. Pensamos, por ejemplo, en todo lo que de esta concentración dice Reimer (1970). La vida, efectivamente, para el que aprende a aprender, está sembrada de situaciones de la más rica variedad en las que podemos aprender, pero la insistencia en la escuela como el lugar por excelencia para el aprendizaje, logra que ni siquiera ahí se lleve a cabo un aprender genuino. De tanto conferirle a la escuela las propiedades de la legítima educación, proceso paralelo con el de desconocerle al resto de la sociedad -hogar, barrio, centros de trabajo, etc.- su potencial educativo, lo que ocurre, al final de cuentas, es que el tan esperado efecto educativo de la escuela se convierta, en muchos casos, en pseudoeducación, quedando el aprendizaje reducido a simple memorización. 


\section{Maximización}

Este principio supone que si "series mayores de producción en la fábrica determinarían costes unitarios más bajos, entonces, por analogía, los aumentos de escala producirían también economías en otras actividades" (Toffler, 1980, 55).

La educación, de acuerdo con el principio de maximización, es una de esas actividades en la que aumentar la escala baja los costos. La idea es, entonces, que el mismo molde sirva para sacar el mayor número de artículos iguales posibles, la más grande promoción posible. Esto obliga a, prácticamente, ignorar la diversidad y a bajar hasta mínimos funcionales las exigencias de calidad.

\section{Centralización}

Esta búsqueda del más requiere de la centralización, el sexto de los principios que, articulados entre sí, hicieron posible el industrialismo de la época moderna. Tenemos, pues, una educación que se nutrió de los principios que le dieron su configuración particular a las sociedades industrializadas, con los resultados conocidos: profesionales producidos en serie, con una visión fragmentaria del mundo y de la vida, funcionando al ritmo de la actividad fabril, concentrados en los centros urbanos, promoviendo el crecimiento cuantitativo y la centralización del poder.

Pero este modelo civilizatorio, esta sociedad de la Segunda ola ha comenzado a dar señales de agotamiento. Ya en 1955, en los Estados Unidos, la cantidad de gente que trabajaba en el sector servicios era superior a la que trabajaba en el sector industrial. Con estos cambios en marcha, también la educación se está viendo obligada a cambiar.

Fiel al paradigma mecanicista y reduccionista, la educación, durante el período industrial, hizo lo que se le pidió: preparar a la gente para que funcionara en un mundo concebido como una máquina, para que fueran piezas de un engranaje, sin importar demasiado que en el cumplimiento de ese propósito, a no pocos, se les tuviera que tratar como a piezas defectuosas. 


\section{La nueva educación holista}

La educación que reclama la sociedad naciente, en cambio, es una educación nueva para una sociedad nueva. La ecología profunda es fuente de principios para la nueva educación. El saber ecológico que ha de permear a la nueva cultura, en general, ha de hacerlo, también, a la educación, en particular.

\section{De la uniformización a la diversificación}

Para el saber ecológico, la diversidad es riqueza, lo que hagamos en contra de la diversidad en sus distintas manifestaciones -biológica, cultural, espiritual- nos empobrece. Es inconcebible, entonces, seguir apoyando e impulsando, desde la educación, la uniformización. La nueva educación holista debe hacer de la diversidad un valor y, de su preservación y enriquecimiento, uno de sus objetivos.

\section{De la especialización a la integralidad}

La ecología nos enseña, también, que un ser vivo especializado es muy vulnerable, es decir, poco adaptable ante los cambios que puedan darse. Pensemos, por ejemplo, en el oso panda gigante que se alimenta, casi exclusivamente, de hojas verdes y brotes de bambú; si el bambú desapareciera por la razón que fuera, la población de los pandas podría morir de hambre.

Con esto en cuenta, la nueva educación debe poner el énfasis, como dice Gallegos (2001), en el aprender y no en el enseñar. El fragmentado saber del especialista lo vuelve rígido, temeroso ante el cambio; por el contrario, el que va más allá del saber especializado, el que no se queda en el detalle, el que aprende a aprender, gana en flexibilidad y asume la posibilidad del cambio no como una amenaza, sino como un reto. 


\section{De la sincronización a la asincronización}

En la era industrial, aprendimos a vivir al ritmo de las máquinas, al compás del tic tac del reloj. Vivir es, en este contexto, vivir sojuzgados por los horarios, por las rígidas jornadas laborales, por cronogramas en los que estaba programada, de antemano, la casi totalidad de la vida de las personas. Este proceso sincronizador tenía en la escuela a un fuerte aliado.

Con el surgimiento de la sociedad postindustrial, con la aparición del nuevo paradigma que la hace posible, la educación no tiene por qué seguir siendo la que prepara a la gente para la vida fabril, la vida rígida, programada y monótona del período industrial; por el contrario, el paradigma emergente reclama una educación centrada en la vida y, por tanto, flexible, espontánea y creativa.

\section{De la concentración a la desconcentración}

Si los comienzos del siglo XIX fueron los años de los grandes encarcelamientos, a nosotros nos corresponde impulsar las grandes liberaciones, soltar amarras, desconcentrar. La nueva educación sólo puede ayudar en este proceso si comienza por desconcentrarse a sí misma. Para ello, debe permitir y posibilitar que el trabajo de educar sea compartido por otras instancias de la sociedad, superar la concepción de la educación escolacéntrica Que no sea sólo asistiendo a la escuela como las personas, legítimamente, puedan educarse, que se acepte y se aproveche que la vida (familiar y social), en su más amplio sentido, es como una gran escuela sin paredes, que vivir es aprender y aprender es vivir. No se puede seguir invisibilizando, como hasta ahora, el papel educativo del entorno extraescolar, como si la televisión, por ejemplo, para bien o para mal, no fuera un fuerte factor educativo. 


\section{Superar la maximización}

Este principio de la maximización constituye un culto al crecimiento cuantitativo, su consigna puede ser enunciada así: cuanto más, mejor. La tierra como ser vivo, convertida en proveedora de recursos para esta insaciable macrofilia, es la gran víctima de esta ideología crecimentista.

El saber ecológico nos da pruebas suficientes y contundentes de que crecer a costa de la vitalidad del Planeta, como lo hemos hecho durante todo el período industrial, es un crecimiento pírrico, dado que el costo ambiental no se compensa con el supuesto beneficio económico que el crecimiento deja. La nueva educación, enriquecida por el saber ecológico, debe revolucionar nuestros valores, sugerir estilos de vida sustentables, despertar expectativas cuya consecución no mine la salud de Gaia, nuestro frágil planeta azul.

\section{De la centralización a la descentralización}

La centralización, por un lado, acumula poder y, por otro, dependencia; la descentralización distribuye el poder y, con ello, ganamos en autonomía. En efecto, el principio centralizador de la era industrial culminaba con la centralización del poder, las decisiones que afectaban a más gente, emanaban de un grupo de personas cada vez más reducido y, en el límite, de una sola. La educación no era la excepción, sino que contribuía, con su currículum oculto, a eso. El presidente le da órdenes al ministro, el ministro a los directores, éstos a los profesores y los profesores a los estudiantes: la famosa estructura piramidal, jerárquica. Lo mínimo que se puede decir de un esquema así, es que coarta la iniciativa y la creatividad de los individuos y de las comunidades.

La nueva educación debe comprometerse con el proceso inverso: descentralizar para promover la iniciativa y la creatividad de las personas y de sus respectivas comunidades. 


\section{Conclusión}

Ninguno de estos principios de nuevo cuño, por sí solo, es suficiente para consolidar un enfoque educativo alternativo; es sólo de su gradual y compleja articulación que puede surgir la nueva educación: esa que hará de la vida y de la preservación de todas las condiciones que la posibilitan y enriquecen su prioridad central.

Esta nueva educación, que las circunstancias actuales reclaman como urgente, difícilmente puede nacer de las mentes que, desde el poder, verticalmente, quieren cambiar las cosas. Sus actuaciones no dejan de darle la razón a Einstein, cuando dijo que no se puede resolver un problema desde el mismo estado de conciencia que lo provocó. Siendo así, lo mejor que podemos hacer es abrir nuestras mentes y nuestros corazones, para ser capaces de reconocer lo nuevo y alternativo ahí donde surja, y de propagarlo con nuestro entusiasmo.

\section{Referencias}

Gallegos, R. (Compil.), Clark, E, Damián, V., Krishna, P., Lee, M., Roberts, T. y Snow, P. (1997). El destino indivisible de la educación. México: Editorial Pax.

Gallegos, R. (2001). Educación holista: Pedagogía del amor universal. México: Editorial Pax.

Marcuse, H. (1969). El hombre unidimensional. Barcelona: Seix Barral.

Ortega y Gasset, J. (2006). La rebelión de las masas. Madrid: Espasa-Calpe.

Panikkar, R. (2005). El silencio de Buda. Madrid: Editorial Siruela.

Reimer, E. (1970). La escuela ha muerto. Barcelona: Barral Editores.

Toffler, A. (1980). La tercera ola. Barcelona: Editorial Plaza y Janés. 